Macromolecular Nanotechnology

\title{
Influence of the modification, induced by zirconia nanoparticles, on the structure and properties of polycarbonate
}

\author{
T.E. Motaung ${ }^{a}$, M.L. Saladino ${ }^{b}$, A.S. Luyt ${ }^{\mathrm{a}, *}$, D. Chillura Martino ${ }^{\mathrm{c}}$ \\ ${ }^{a}$ Department of Chemistry, University of the Free State (Qwaqwa Campus), Private Bag X13, Phuthaditjhaba 9866, South Africa \\ ${ }^{\mathrm{b}}$ Centro Grandi Apparecchiature-UniNetLab, University of Palermo, Via F. Marini 14, Palermo I-90128, Italy \\ ${ }^{\mathrm{c}}$ Dipartimento di Scienze e Tecnologie Biologiche, Chimiche e Farmaceutiche, Università di Palermo, e INSTM UdR - Palermo, Parco d'Orleans II, \\ Viale delle Scienze pad.17, Palermo I-90128, Italy
}

\section{A R T I C L E I N F O}

\section{Article history:}

Received 13 August 2012

Received in revised form 27 March 2013

Accepted 22 April 2013

Available online 9 May 2013

\section{Keywords:}

Nanocomposites

Polycarbonate

Zirconia

Degradation

Interfacial interaction

\begin{abstract}
A B S T R A C T
Melt compounding was used to prepare polycarbonate (PC)-zirconia nanocomposites with different amounts of zirconia. The effect of the zirconia loading, in the range of 1-5 wt.\%, on the structure, mechanical properties and thermal degradation kinetics was investigated. The zirconia nanoparticle aggregates were well dispersed in the PC matrix and induced the appearance of a local lamellar order in the polycarbonate as inferred by SAXS findings. This order could be a consequence of the intermolecular interactions between zirconia and the polymer, in particular with the quaternary carbon bonded to the methyl groups and the methyl carbon as inferred from the NMR results. The presence of zirconia caused a decrease in the storage and loss moduli below the glass transition temperature. However, the highest amount of zirconia increased the modulus. The presence of zirconia in PC slightly increased the thermal stability, except for the highest zirconia content which showed a decrease. The activation energies of thermal degradation for the nanocomposites were significantly lower than that for pure PC at all degrees of conversion.
\end{abstract}

(c) 2013 Elsevier Ltd. All rights reserved.

\section{Introduction}

Polycarbonate (PC) is an amorphous and inexpensive polymer known for its excellent optical and mechanical properties. PC nanocomposites have shown potential applications in UV protecting sheets and films [1-4]. There are a number of recent papers reporting on the mechanical properties, thermal stability and flame retardancy of PC nanocomposites containing different metal oxide nanoparticles [5-10]. The results indicate that metal oxides have an effect on the morphology, as well as mechanical and thermal behavior of PC. Some authors found that the well dispersed metal oxide nanoparticles in PC improved its surface, viscoelastic, and mechanical properties, and increased its thermal stability. They related these observa-

\footnotetext{
* Corresponding author. Tel.: +27 857185314; fax: +27 857185444

E-mail address: LuytAS@qwa.ufs.ac.za (A.S. Luyt).
}

tions to the strong interactions at the polymer-filler interface [8-11].

PC-zirconia nanocomposites are promising materials due to the interesting optical properties of the final product [12-14]. The nanocomposites prepared by in situ polymerization were found to be highly transparent with up to 50 wt.\% $\mathrm{ZrO}_{2}$ nanoparticles, and exhibited good thermal stability, hardness and elastic modulus. These results were attributed to the interfacial interaction between the polymer and the nanoparticles. However, the hardness and thermal stability of the nanocomposites considerably decreased at high filler contents [12,13]. The deterioration in hardness was related to the agglomeration of the $\mathrm{ZrO}_{2}$ nanoparticles in the polymer matrix, and the decrease in thermal stability to the evaporation of the entrapped organic solvent in $\mathrm{ZrO}_{2}$ agglomerates and/or the unreacted monomer because of the low final conversion. Imai et al. [12] also modified the polycarbonate with sulphonic acid, 
and this was found to further reduce the thermal stability of the matrix polymer.

The purpose of this study was to obtain a deeper understanding of the interfacial interaction between zirconia nanoparticles and $\mathrm{PC}$ in $\mathrm{PC}-\mathrm{ZrO}_{2}$ nanocomposites prepared through a melt compounding method. The effect of the presence and amount of zirconia nanoparticles, prepared using a sol-gel method, on the structure, thermal and mechanical properties, as well as the thermal degradation kinetics, of the PC was investigated. The composites were characterized using transmission electron microscopy (TEM), X-ray diffractometry (XRD), Small Angle X-ray Scattering (SAXS), dynamic mechanical analysis (DMA), thermogravimetric analyses (TGA), and ${ }^{13} \mathrm{C}$ cross-polarization magic-angle spinning nuclear magnetic resonance $\left({ }^{13} \mathrm{C}\left\{{ }^{1} \mathrm{H}\right\}\right.$ CP-MAS NMR).

\section{Experimental}

\subsection{Materials}

Tetra- $n$-propylzirconate (Aldrich), capronic acid (Aldrich), ethanol (Eurobase), ammonium hydroxide (Aldrich) were used as received without further purification. Commercial grade bisphenol-A polycarbonate (PC, Makrolon ${ }^{\circledR}$ 2407 produced by Bayer Material Science, Germany and having a melt flow rate at $300{ }^{\circ} \mathrm{C} / 1.2 \mathrm{~kg}$ of $20 \mathrm{~g} / 10 \mathrm{~min}$ ) was used in pellet form. The resin was dried at $120^{\circ} \mathrm{C}$ overnight under static vacuum before processing.

\subsection{Zirconia preparation}

The $\mathrm{ZrO}_{2}$ nanoparticles were prepared according to the method reported by Bondioli et al. [15]. The zirconia nanoparticles were precipitated by slow addition of an alcoholic solution containing capronic acid and tetra- $n$-propylzirconate, previously reacted for $30 \mathrm{~min}$ at room temperature, to a mixture of ethanol and water.

\subsection{Composites preparation}

The PC pellets were thoroughly mixed with 1,2 and $5 \mathrm{wt} . \%$ zirconia for $10 \mathrm{~min}$ at $240{ }^{\circ} \mathrm{C}$ and $30 \mathrm{rpm}$ in a $50 \mathrm{~mL}$ internal mixer of a Brabender Plastograph (Duisburg, Germany). The total batch size was approximately $40 \mathrm{~g}$. The mixed samples were melt-pressed into $150 \times 150 \mathrm{~mm}^{2}, 1 \mathrm{~mm}$ thick sheets at $240{ }^{\circ} \mathrm{C}$ for $5 \mathrm{~min}$.

\subsection{Analysis methods}

TEM micrographs were acquired using a JEM-2100 (JEOL, Japan) electron microscope operating at $200 \mathrm{kV}$ accelerating voltage. The obtained nanocomposites were cut into $100 \mathrm{~nm}$ thick slices using a Leica EM UC6 ultramicrotome. Slices were put onto a $3 \mathrm{~mm} \mathrm{Cu}$ grid "lacey carbon" for analysis.

XRD patterns were recorded in the $2-70^{\circ} 2 \theta$ range at steps of $0.05^{\circ}$ and a counting time of 5 s/step in a Philips PW 1050 diffractometer, equipped with a $\mathrm{Cu}$ tube and a scintillation detector beam. The X-ray generator worked at $40 \mathrm{kV}$ and $30 \mathrm{~mA}$. The instrument resolution (divergent and antiscatter slits of $0.5^{\circ}$ ) was determined using standards free from the effect of reduced crystallite size and lattice defects.

SAXS measurements were taken using a Bruker AXS Nanostar-U instrument whose source was a $\mathrm{Cu}$ rotating anode working at $40 \mathrm{kV}$ and $18 \mathrm{~mA}$. The X-ray beam was monochromatized at a wavelength $\lambda$ of $1.54 \AA(\mathrm{Cu} \mathrm{K} \alpha)$ using a couple of Göbel mirrors and was collimated using a series of three pinholes with diameters of 500, 150 and $500 \mu \mathrm{m}$. Samples were directly mounted on the sample stage to avoid additional scattering of the holder. Data were collected at room temperature for $1000 \mathrm{~s}$ by using a two-dimensional multiwire proportional counter detector placed at $24 \mathrm{~cm}$ from the sample allowing the collection of data in the $Q$ range $0.02-0.78 \AA$. The measurements were repeated in two different portions of each sample to check its homogeneity.

${ }^{13} \mathrm{C}$ cross polarization - magic angle spinning nuclear magnetic resonance $\left({ }^{13} \mathrm{C}\left\{{ }^{1} \mathrm{H}\right\}\right.$ CP-MAS NMR) spectra were obtained at room temperature with a Bruker Avance II $400 \mathrm{MHz}(9.4 \mathrm{~T})$ spectrometer operating at $100.63 \mathrm{MHz}$ for the ${ }^{13} \mathrm{C}$ nucleus with a MAS rate of $8 \mathrm{kHz}, 500$ scans, a contact time of $1.5 \mathrm{~ms}$ and a repetition delay of $2 \mathrm{~s}$. The optimization of the Hartmann-Hahn condition [16] was obtained using an adamantine sample. Each sample was placed in a $4 \mathrm{~mm}$ zirconia rotor with KEL-F caps using silica as filler to avoid inhomogeneities inside the rotor. The proton spin-lattice relaxation time in the rotating frame $\mathrm{T}_{1 \rho}(\mathrm{H})$ was indirectly determined, with the variable spin lock (VSL) pulse sequence, by the carbon nucleus observation using a $90^{\circ}-\tau$-spin-lock pulse sequence prior to crosspolarization [17]. The data acquisition was performed by ${ }^{1} \mathrm{H}$ decoupling with a delay time, $\tau$, ranging from 0.1 to $7.5 \mathrm{~ms}$ and a contact time of $1.5 \mathrm{~ms}$. The proton spin-lattice relaxation time in the laboratory frame $T_{1}(H)$ was determined, using the saturation recovery pulse sequence [18], by the carbon nucleus observation using a $90^{\circ}-\tau-90^{\circ}$ pulse sequence prior to cross polarization with a delay time $\tau$ ranging from 0.01 to $3 \mathrm{~s}$. The ${ }^{13} \mathrm{C}$ spin-lattice relaxation time in the rotating frame $T_{1 \rho}(C)$ was determined, with the variable spin lock (VSL) pulse sequence, applying the spin-lock pulse after the cross-polarization on the carbon channel [17]. The data acquisition was performed by ${ }^{1} \mathrm{H}$ decoupling with a spin lock pulse length, $\tau$, ranging from 0.4 to $30 \mathrm{~ms}$ and a contact time of $1.5 \mathrm{~ms}$. The cross polarization time $\mathrm{T}_{\mathrm{CH}}$ values for all the carbon signals of PC were obtained through variable contact time (VCT) experiments [19]. The contact times used in the VCT experiments were $0.05,0.1,0.2,0.3,0.4,0.5,0.6,0.8,1.0,1.2,1.5,2.0,2.5,3.0$, $3.5,4.0,4.5,5.0,6.0$ and $7.0 \mathrm{~ms}$.

The dynamic mechanical analysis of the blends and composites were performed between 40 and $180^{\circ} \mathrm{C}$ in the bending mode at a heating rate of $5{ }^{\circ} \mathrm{C} \mathrm{min}^{-1}$ and a frequency of $1 \mathrm{~Hz}$ using a Perkin Elmer Diamond DMA (Waltham, Massachusetts, USA).

Thermogravimetric analysis (TGA) was done in a Perkin Elmer TGA7 (Waltham, Massachusetts, USA) under flowing nitrogen at a constant flow rate of $20 \mathrm{~mL} \mathrm{~min}^{-1}$. Samples (5-10 mg) were heated from 25 to $600{ }^{\circ} \mathrm{C}$ at different heating rates. The degradation kinetic analysis was performed 
using the Flynn-Wall-Ozawa (FWO) and the KissingerAkahira-Sunose (KAS) methods, described elsewhere [20].

TGA combined with Fourier-transform infrared (FTIR) spectroscopy (TGA-FTIR) analyses were performed using a Perkin Elmer STA6000 simultaneous thermal analyzer (Waltham, Massachusetts, USA) under flowing nitrogen at a constant flow rate of $20 \mathrm{~mL} \mathrm{~min}^{-1}$. Samples (20$25 \mathrm{mg}$ ) were heated from 30 to $600{ }^{\circ} \mathrm{C}$ at $10^{\circ} \mathrm{C} \mathrm{min}{ }^{-1}$ and held for $4 \mathrm{~min}$ at $600^{\circ} \mathrm{C}$. The furnace was linked to an FTIR spectrometer (Perkin Elmer Spectrum 100, Massachusetts, USA) with a gas transfer line. The volatiles were scanned over a $400-4000 \mathrm{~cm}^{-1}$ wavenumber range at a resolution of $4 \mathrm{~cm}^{-1}$. The FTIR spectra were recorded in the transmittance mode at different temperatures during the thermal degradation process.

\section{Results and discussion}

The TEM micrographs of the $\mathrm{ZrO}_{2}$ powder, reported in our previous paper [21], showed aggregates with a large number of particles (more than 30) of different sizes. In each aggregate the bigger, quite thick particles (around 200-400 nm) were surrounded by smaller spongy particles $(50-100 \mathrm{~nm})$. The TEM micrographs of the PC- $\mathrm{ZrO}_{2}$ nanocomposite having $5 \mathrm{wt}$ \% of zirconia are reported in Fig. 1. The histogram, shown in Fig. 2, was obtained after analyzing several micrographs and depicts a relatively uniform and large particle size distribution. It seems as if the aggregates broke up into single particles and the particles dispersed in the polymer matrix. This could be a consequence of the interaction between the nanoparticles and the polymer matrix. At higher magnification it can be seen that the nanoparticles are constituted of several crystalline domains of about $5 \mathrm{~nm}$ whose atomic planes are visible in Fig. 1E.

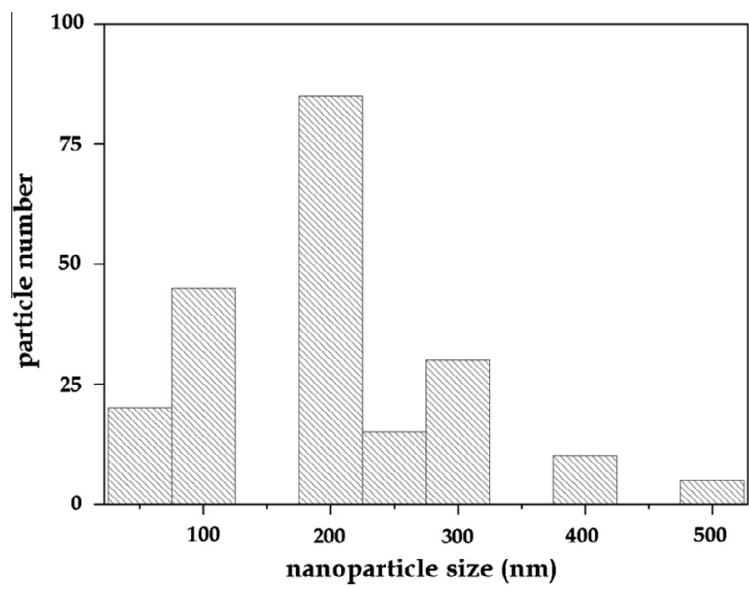

Fig. 2. Size distribution of zirconia nanoparticles in the $95 / 5 \mathrm{w} / \mathrm{w}$ PC$\mathrm{ZrO}_{2}$ nanocomposite.

It is expected that if interaction occurs at the interface, the nanoparticles could induce a change in the polymer structure. For this reason, XRD patterns were registered (Fig. 3). The pattern of the zirconia powder indicated that the zirconia consisted of $80 \mathrm{wt}$.\% of tetragonal zirconia and $20 \mathrm{wt} . \%$ of monoclinic Baddeleyite, as reported in a previous paper [14]. The diffraction pattern of PC shows an intense broad diffraction peak around $17^{\circ}$, a shoulder around $26^{\circ}$ and another broad peak at $44^{\circ}$. The diffraction peak is superimposable on the WAXS pattern reported in literature [22], and is typical of an amorphous material. The XRD patterns of the $\mathrm{PC}-\mathrm{ZrO}_{2}$ nanocomposites having 1, 2 and 5 wt.\% of $\mathrm{ZrO}_{2}$ do not show the characteristic peak of zirconia as a consequence of the low amount of small zirconia nanoparticles. The typical PC diffraction peaks do
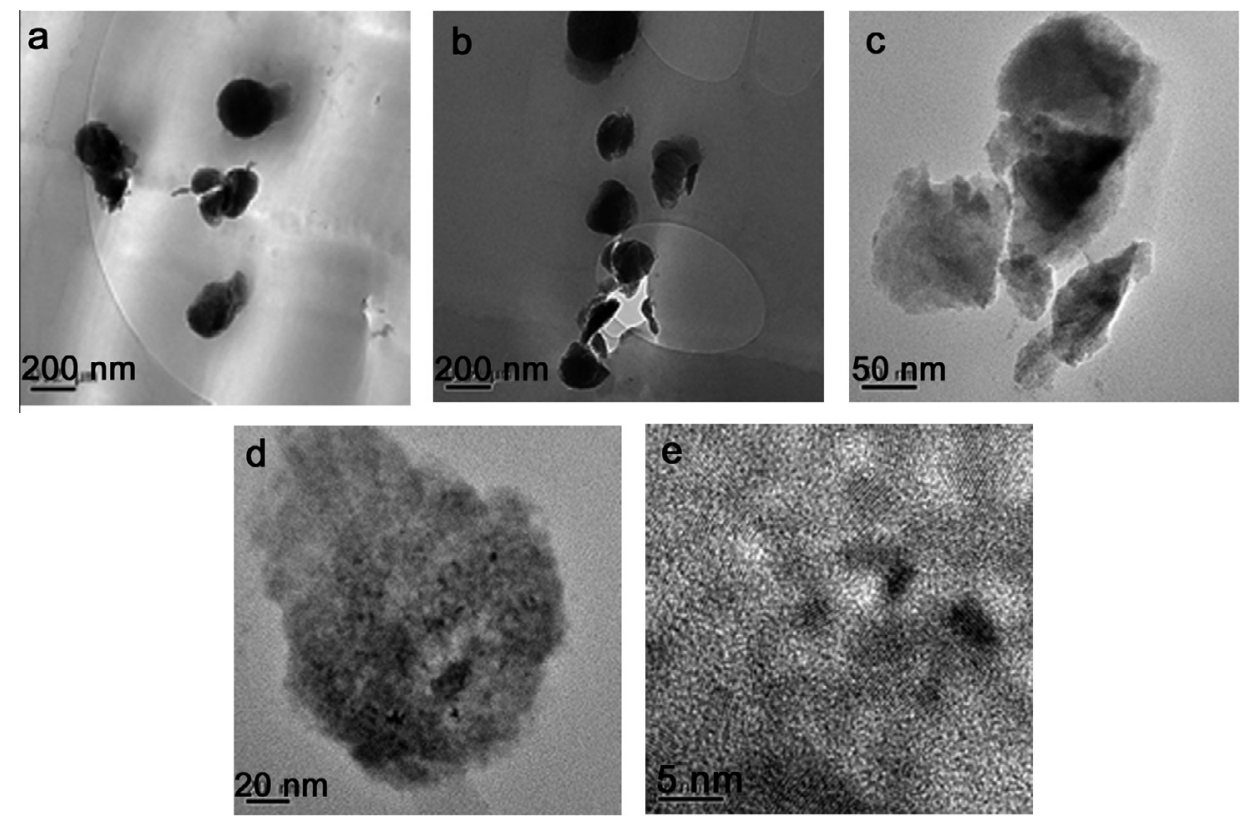

Fig. 1. TEM micrographs of the $95 / 5 \mathrm{w} / \mathrm{w} \mathrm{PC}-\mathrm{ZrO}_{2}$ nanocomposite. 


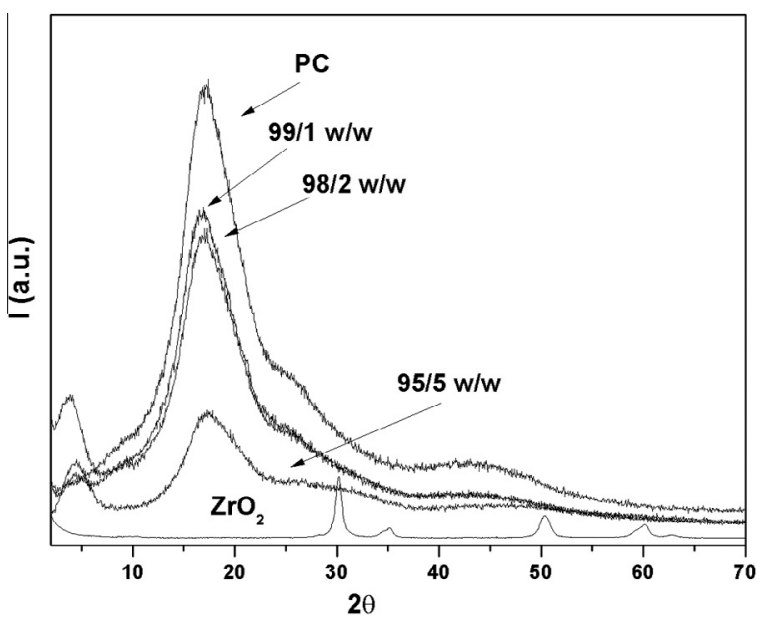

Fig. 3. XRD patterns of zirconia powder, pure $P C$ and the $P C-\mathrm{ZrO}_{2}$ composites.

not undergo any significant change, except for a decrease in intensity with an increase in the amount of zirconia. This cannot be explained by simply considering the variation in the electron scattering density. In fact, it does not linearly change with composition. Furthermore, a broad peak appears at about $3.7^{\circ}$, the intensity of which increases with the amount of zirconia. It indicates the presence of a repeating distance which cannot be ascribed to either the crystalline structure of the nanoparticles or to the nanoparticle clustering. In fact, even assuming that the nanoparticles were in contact, the peak position, evaluated on the basis of the nanoparticle size from the TEM micrographs, should fall at $0.018^{\circ}$, which is well below the observed value. It follows that it has to be ascribed to some structure induced in the polymer by the presence of the zirconia. The peak shape is similar to that observed by SAXS on crystalline PC [23], and which was ascribed to a lamellar structure. This finding suggests that the zirconia induced a local crystallization in the polymer. It has to be noticed that the scattering peak reported in literature indicates a long period distance of about $120 \AA$, which is almost 4 times the distance (c.a. $30 \AA$ ) evaluated form the peak position in the diffraction data.

In order to get more clarity on this aspect, SAXS measurements were performed. The SAXS two-dimensional patterns of the nanocomposites, recorded at $24 \mathrm{~cm}$ sample to detector distance, displayed an isotropic halo which indicates that no preferred crystallization occurred. They were radially averaged, which gives a scattering intensity $I(Q)$ in the $0.02-0.77 \AA^{-1} Q$ range. $Q$, the momentum transfer, is equal to $(4 \pi \sin \theta) / \lambda$, where $2 \theta$ is the scattering angle. Measurements, carried out on different portions of the samples, were superimposable thus confirming that the samples were homogeneous. A comparison of the SAXS experimental data of the pure PC and the composite samples, after correction for the transmission, the thickness of the samples and for mylar, is shown in the Fig. 4.

The SAXS profiles show a monotonic decrease at low Qvalues followed by a peak, the intensity of which increases with the amount of zirconia nanoparticles, thus confirming
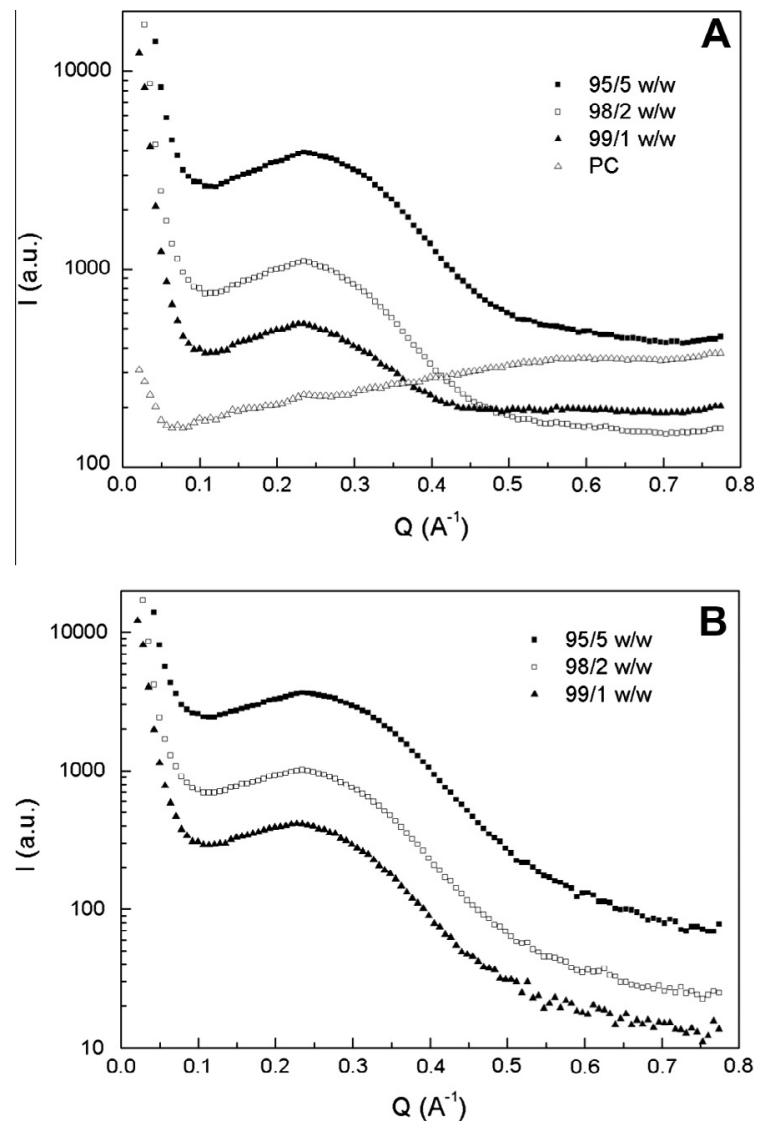

Fig. 4. (A) SAXS intensities vs. Q of PC and the composites; (B) SAXS intensities vs. Q for the composites after subtracting the PC contribution.

the XRD data. A shoulder appears in the range 0.5-0.77. It can be ascribed to some small angle scattering due to the amorphous PC. The PC intensity, properly weighted, was therefore subtracted from the ones for the composites. The corrected curves are shown in Fig. 3B. Since the lowangle region of the pattern is dominated by a single peak, the presence of a cubic arrangement was excluded and, in agreement with literature [23], it was considered that the backbones of the polymer could arrange to form lamellae. On this basis, the model proposed by Nallet et al. [24] was considered.

$I(Q)=\frac{A}{\left(Q \xi_{p}\right)^{2}+1}+\frac{B}{\left(Q-Q_{M}\right)^{2} \xi_{l}^{2}+1}+B k$

where the first term represents the quasi-Bragg peak due to the stacking of the lamellar layers, the second the quasi-Bragg peak due to the stacking of the lamellar layers, and $B k$ the incoherent scattering plus the instrumental noise. $A$ and $B$ correspond to the scattering intensities from the diffuse scattering and the quasi-Bragg scattering, $\xi_{l}$ is the spatial correlation length of the lamellar layers, and $Q_{\max }$ is the $Q$ value corresponding to the peak intensity. The intensities for the three composites computed by means of Eq. (1) poorly reproduce the experimental values 


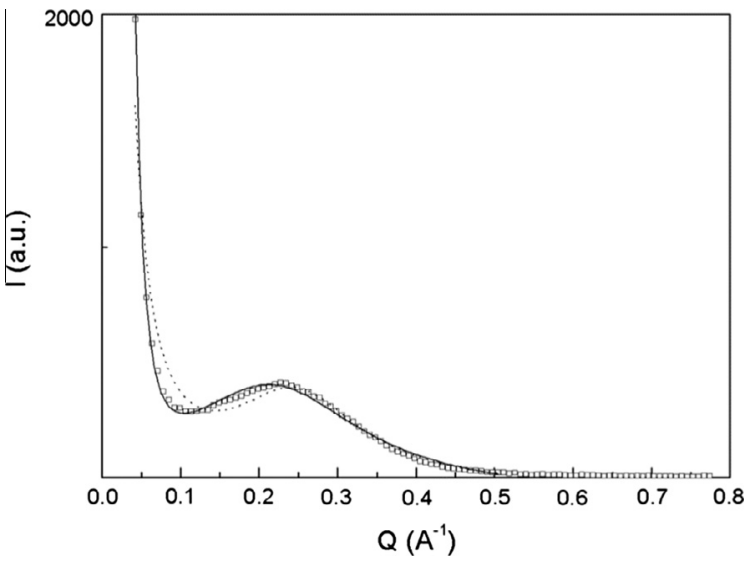

Fig. 5. SAXS intensity vs. $\mathrm{Q}$ of the $99 / 1 \mathrm{w} / \mathrm{w} \mathrm{PC}-\mathrm{ZrO}_{2}$ nanocomposite. Squares: experimental intensity; dotted line: fit by means of Eq. (1); continuous line: fit by means of Eq. (2).

as indicated by the dotted line reported in Fig. 5 as an example for the 99/1 w/w PC-zirconia nanocomposite.

In our opinion the observed small-angle diffuse scattering does not depend on a density fluctuation in the polymer, but on the formation of a well-defined nanoparticle-polymer interface. On this basis, we modified the Nallet model by considering that the diffuse small-angle scattering could be described by means of a Porod contribute. The resulting equation is:

$I(Q)=\frac{B}{\left(Q-Q_{M}\right)^{2} \xi_{l}^{2}+1}+\frac{F}{Q^{4}}+B k$

where the meaning of $B, \xi_{l}, Q_{M}$ and $B k$ are as described above, $F$ is equal to $N_{\rho} \Delta \rho^{2} S$ where $N_{\rho}$ is the particle number density, $\Delta \rho^{2}$ is the contrast i.e. the square of the difference between the electron density of the particle and that of PC, and $S$ is the interfacial area. The intensity computed by this model well reproduces the experimental one for the three nanocomposites. As an example the intensity computed by means of Eq. (2) (continuous line) is compared with the experimental one for the 99/1 w/w PC-zirconia composite in Fig. 5. The values of the fit parameters are reported in Table 1 . From the peak position $\left(Q_{M}\right)$, using Bragg's equation, a repeat distance d of about $28 \AA$ was determined. These results are in fairly good agreement with literature data where a cluster size of $30 \AA$, composed of crystalline PC in a PCL-PC blend, was detected [23]. These clusters are correlated over a length of about $8 \AA$. These findings confirm that the zirconia nanoparticles in-

Table 1

The values of the fit parameters of the composites.

\begin{tabular}{llll}
\hline & $99 / 1 \mathrm{w} / \mathrm{w} \mathrm{PC}-\mathrm{ZrO}_{2}$ & $98 / 2 \mathrm{w} / \mathrm{w} \mathrm{PC}-\mathrm{ZrO}_{2}$ & $95 / 5 \mathrm{w} / \mathrm{w} \mathrm{PC}-\mathrm{ZrO}_{2}$ \\
\hline$B$ & $420(10)$ & $1000(20)$ & $3660(80)$ \\
$Q_{M}$ & $0.223(1)$ & $0.217(3)$ & $0.226(2)$ \\
$\xi_{I}$ & $7.6(4)$ & $8.6(3)$ & $8.2(2)$ \\
$B k$ & $90(10)$ & $10(1)$ & $10(1)$ \\
$F$ & $0.00614(3)$ & $0.0131(2)$ & $0.058(3)$ \\
$R^{2}$ & 0.998 & 0985 & 0995 \\
\hline
\end{tabular}

duce lamellar crystallization in the amorphous polymer through the formation of correlated clusters over a very small distance. These findings could explain the appearance of the peak at $3.7^{\circ}$ in the XRD patterns. Since the shape and position of the amorphous PC peaks in the XRD patterns do not change, it indicates that the long range structure holds. The fact that the intensity does not linearly decrease with filler amount could be a consequence of both the contrast variation and the short range lamellar order which developed in the presence of the zirconia nanoparticles.

The TGA curves of the pure PC and the PC-zirconia nanocomposites are shown in Fig. 6. All the samples show single-step degradation, and the presence of the filler in PC shows a slight increase in thermal stability, except for the $5 \%$ filler containing nanocomposite which shows an observable decrease in thermal stability. According to McNeill and Rincon [25] the main products of decomposition of bisphenol A PC consist of cyclic dimers plus bisphenol A, together with smaller amounts of volatile products including carbon dioxide, p-cresol, p-ethyl phenol, phenol, p-vinyl phenol, p-isopropyl phenol, carbon monoxide and methane. They further suggested that the nature and wide range of products indicates that the decomposition in the absence of air and moisture probably proceeds mainly by homolysis of the polymer chain and reactions of the radicals so formed. Strong interaction between these radicals and the zirconia particles would reduce their mobility and retard the degradation process. Since TGA measures mass loss, interaction between the volatile degradation products and the zirconia particles would retard the volatilization of these degradation products, which would also increase the 'degradation' temperature, which in a TGA analysis is actually the temperature where mass loss is detected. In our case the free radicals formed during degradation, and the volatile degradation products, did not seem to interact very strongly with the nanoparticles since the mass loss temperature range of the PC was not significantly increased when zirconia nanoparticles were present.

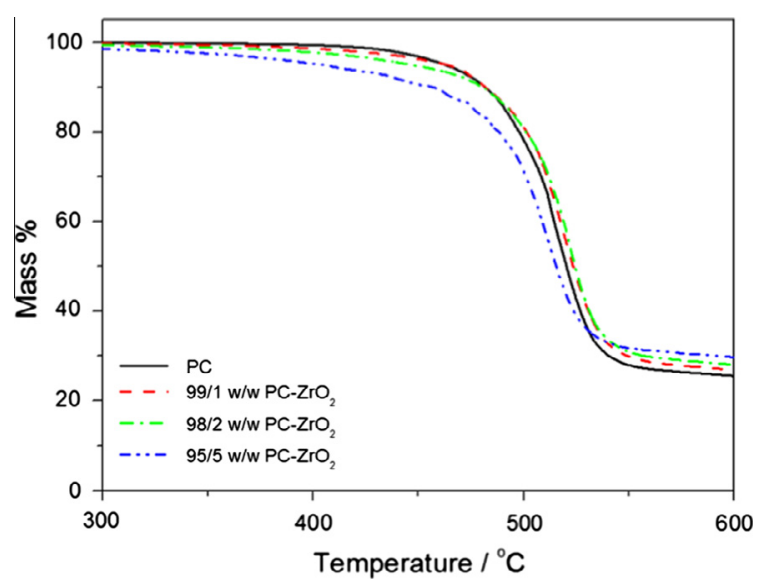

Fig. 6. TGA curves of $\mathrm{PC}$ and the PC-zirconia-PC nanocomposites. 
The isoconversional graphs of $\ln \beta$ versus $1 / T$ and of $\ln$ $\left(\beta / T^{2}\right)$ versus $1 / \mathrm{T}$ were plotted from the TGA curves of PC, 98/2 w/w PC-zirconia and 95/5 w/w PC-zirconia at heating rates of $3,5,7$ and $9{ }^{\circ} \mathrm{C} \mathrm{min}^{-1}$. The activation energy values were calculated from the slopes of the isoconversional plots. Both isoconversional methods give similar values of the activation energies within experimental uncertainty. Fig. 7 illustrates the relationship between the activation energies and the degree of conversion. The activation energy values of pure PC and its nanocomposites generally show an increase with the degree of conversion and fall within the range of activation energies for PC degradation reported previously $[7,26]$. The activation energy values of the pristine PC are lower than that of the $98 / 2$ w/w PC-zirconia nanocomposite, but they are almost the same above $40 \%$ mass loss. The $95 / 5 \mathrm{w} / \mathrm{w}$ PC-zirconia nanocomposite shows much lower values than the pristine PC and the 98/2 w/w PC-zirconia nanocomposite over the whole degree of conversion range. These observations can be explained by the fact that the agglomerated zirconia particles in some way reduced the thermal stability by catalyzing the degradation reactions. Such a catalytic effect has been reported by other authors and quoted in our previous paper on PMMA-zirconia nanocomposites [21].

The increase in activation energy with an increase in degree of conversion was also observed by us when investigating PMMA-SiO $2 / \mathrm{TiO}_{2} / \mathrm{ZrO}_{2}$ nanocomposites $[20,21,27]$ and also by other authors [28,29]. It was generally explained as changes in the degradation mechanism with increasing degree of conversion. An earlier study on the thermal degradation mechanism of bisphenol-A polycarbonate reported that carbonate linkages are the major points of degradation at lower temperatures $\left(<400{ }^{\circ} \mathrm{C}\right)$, while at higher temperatures the isopropylidene group is also susceptible to loss of methyl radicals [30]. Below $500{ }^{\circ} \mathrm{C}$, no free radical reactions were observed for the carbonate group, but rearrangement of the carbonate moiety prevailed. It is quite possible that the char formed during the degradation of PC retarded the movement of the free radicals, which led to the observed increase in activation energy with an increase in degree of conversion. The high-

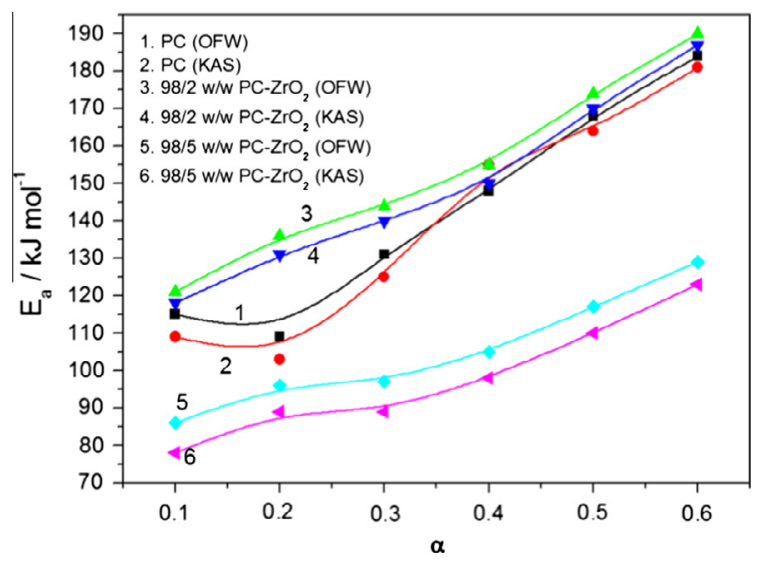

Fig. 7. $E_{a}$ values obtained by the OFW and KAS degradation kinetics methods.

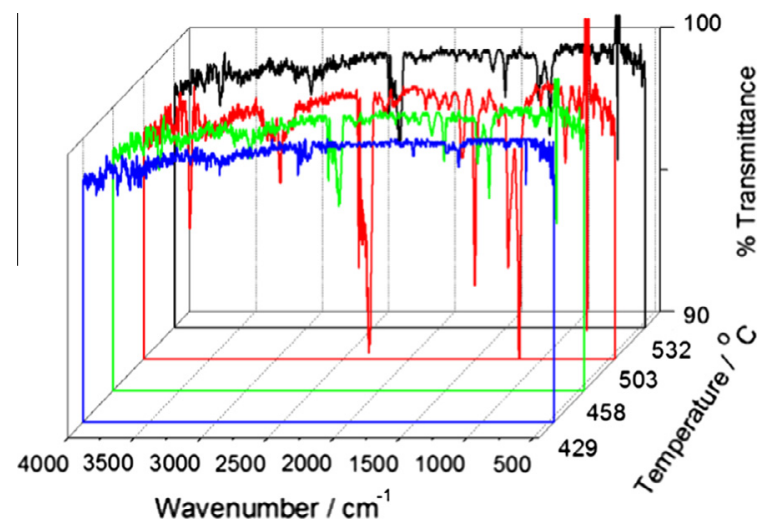

Fig. 8. FTIR curves at different temperatures during the thermal degradation of $\mathrm{PC}$ in a TGA at a heating rate of $10^{\circ} \mathrm{C} \mathrm{min}^{-1}$.

er activation energy values for the $98 / 2 \mathrm{w} / \mathrm{w} \mathrm{PC}-\mathrm{ZrO}_{2}$ can be attributed to interaction between the nanoparticles, the free radicals formed during PC degradation (which led to trapping of free radicals by the nanoparticles), and the volatile substance. The lower activation energy values for the $95 / 5 \mathrm{w} / \mathrm{w} \mathrm{PC}-\mathrm{ZrO}_{2}$ nanocomposite may be related to a catalytic effect of the nanoparticles on the PC degradation. It seems as if there are two opposing effects that play a role in the degradation of PC in the presence of zirconia. More char formation leading to a retardation of the degradation process seems to be prevalent at low zirconia contents where the extent of filler agglomeration is lower, while the zirconia predominantly acts as a catalyst at higher filler contents where there are higher extents of agglomeration.

TGA-FTIR analyses were done to establish the nature of the degradation product(s), and to confirm the observations from the kinetic analysis of the thermal degradation process of PC and the PC-zirconia nanocomposites. Fig. 8 shows the FTIR spectra of the degradation products of pure PC at different temperatures during the degradation process. All the spectra almost perfectly match the known spectrum for the thermal decomposition of bisphenol- $A$ polycarbonate in which $\mathrm{CO}_{2}$, phenol and bisphenol $\mathrm{A}$ are the main volatile products. Some band assignments are listed in Table 2.

No new peaks or peak shifts were observed for the nanocomposite sample. There is a clear increase in peak intensity for all the characteristic peaks with increasing temperature, it reaches a maximum, and decreases again

Table 2

FTIR band assignments for PC.

\begin{tabular}{ll}
\hline Wavenumber $\left(\mathrm{cm}^{-1}\right)$ & Assigned vibrations \\
\hline 3658 & Free alcohols (aliphatic substituted phenol) \\
2974 & $\mathrm{C}-\mathrm{H}$ stretching \\
$2388-2119$ & Asymmetric stretching mode of $\mathrm{CO}_{2}$ \\
1606 & Ring stretching \\
1509 & Skeletal vibration of phenyl compounds \\
1257 & Aromatic ether stretch \\
1182 & Carbon hydroxyl stretching band \\
833 & Bending mode of $\mathrm{CO}_{2}$ \\
\hline
\end{tabular}




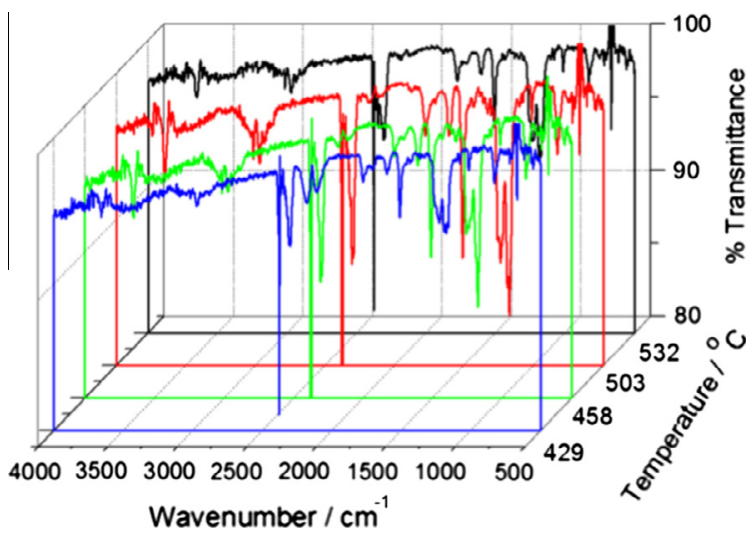

Fig. 9. FTIR curves at different temperatures during the thermal degradation of PC with $5 \mathrm{wt} . \%$ zirconia in a TGA at a heating rate of $10^{\circ} \mathrm{C} \mathrm{min}^{-1}$.

with further increase in temperature. The 95/5 w/w PCzirconia sample shows the same spectra and a similar trend (Fig. 9). The peaks at $429^{\circ} \mathrm{C}$ for PC are less intense than the corresponding peaks of the PC in the nanocomposite. The intensities of the peaks for PC seem to reach a maximum between 503 and $532{ }^{\circ} \mathrm{C}$, while the maximum position for the nanocomposite seems to occur around $458{ }^{\circ} \mathrm{C}$. This suggests that the degradation process is accelerated when zirconia nanoparticles are present, which supports the TGA and degradation kinetics data and explanation.

The DMA curves of the pure PC, and the PC-zirconia nanocomposite having $5 \mathrm{wt} . \%$ of zirconia are shown in Fig. 10. The nanocomposite has higher storage modulus values over the whole temperature range, but the difference is significant during and above the glass transition. The formation of crystalline domains around the nanoparticles, which effectively improved the interaction between the zirconia particles and the polymer chains, is the most probable reason for the higher storage modulus values in the case of the nanocomposite. Both the loss modulus and $\tan \delta$ curves show a higher glass transition temperature for the PC in the nanocomposite. This supports the explanation of a fairly strong interaction between the zirconia particles and the PC chains, which reduced the mobility of the polymer chains.

Since there is evidence that a local ordered structure is induced by the nanoparticles, ${ }^{13} \mathrm{C}\left\{{ }^{1} \mathrm{H}\right\} \mathrm{CP}$-MAS NMR measurements were performed in order to understand at which molecular level the interactions occur, and to attempt to find a correlation between the mechanical properties, the kinetics of degradation and the molecular structure of the polymer. The ${ }^{13} \mathrm{C}\left\{{ }^{1} \mathrm{H}\right\}$ CP-MAS NMR spectra of the $\mathrm{PC}-\mathrm{ZrO}_{2}$ composite loaded with $5 \mathrm{wt}$.\% of zirconia are reported in Fig. 11. Five peaks are present in the spectra: peak 1 at $149 \mathrm{ppm}$ is related to the quaternary carbons of the aromatic rings and to the carbonyl carbon, peak 2 at $127 \mathrm{ppm}$ to the aromatic carbon in meta to the oxygen, peak 3 at $120 \mathrm{ppm}$ to the aromatic carbon ortho to the oxygen, peak 4 at $42 \mathrm{ppm}$ to the quaternary carbon bonded to the methyl groups, and peak 5 at $31 \mathrm{ppm}$ to the methyl carbons, according to literature [31]. No modifica-
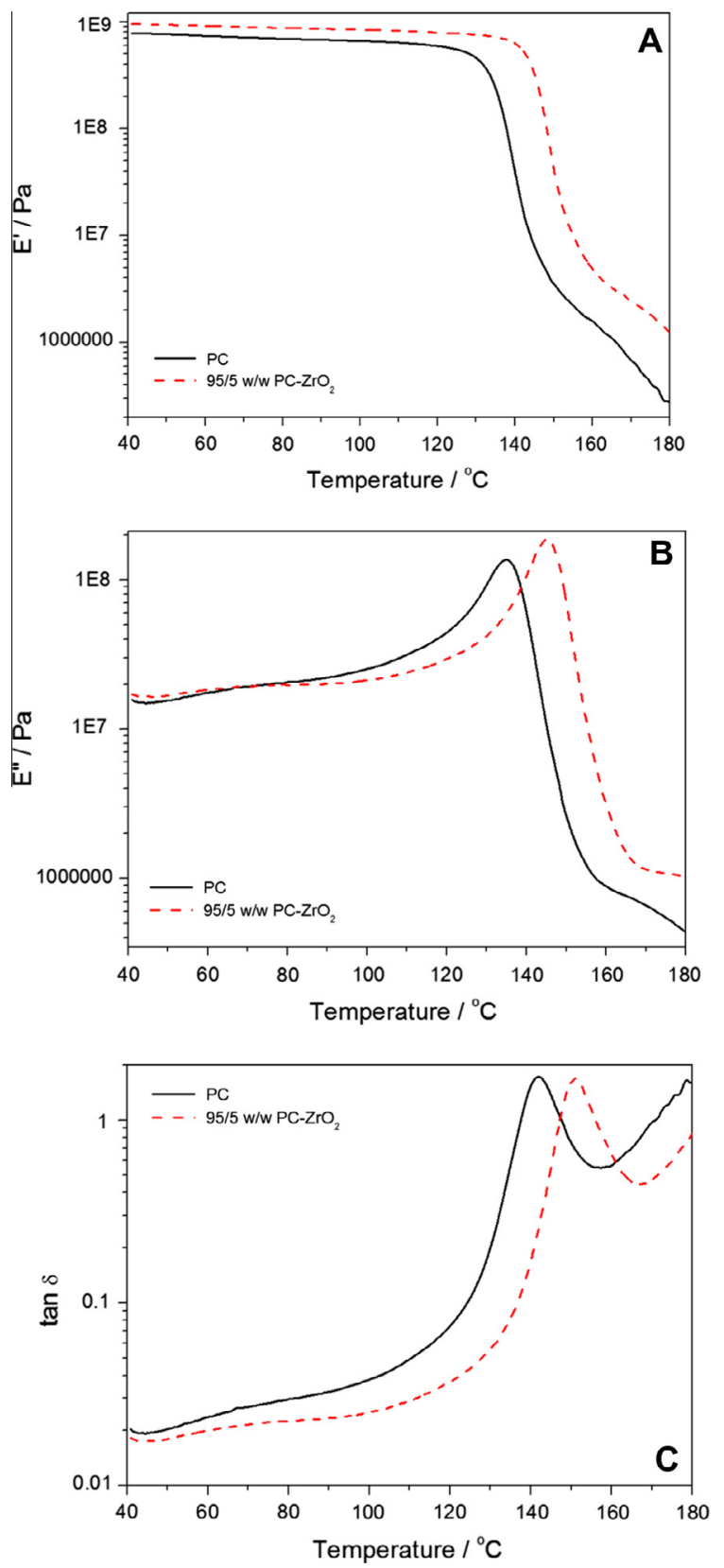

Fig. 10. (A) Storage modulus, (B) loss modulus and (C) $\tan \delta$ curves of PC and $95 / 5 \mathrm{w} / \mathrm{w}$ PC-zirconia.

tion in the chemical shift and in the band shape is observed in the spectrum of the PC-zirconia nanocomposite, indicating that no chemical modification occurred in the polymer. Thus, the relaxation times in the laboratory frame $T_{1}(H)$, in the rotating frame $T_{1 \rho}(H)$, and $T_{1 \rho}(C)$ and the cross-polarization time $\mathrm{T}_{\mathrm{CH}}$ were determined through solid-state NMR measurements in order to evaluate the dynamic modifications occurring in the polymeric chain of the PC matrix after composite formation. The $\mathrm{T}_{1}(\mathrm{H}), \mathrm{T}_{1 \rho}(\mathrm{H}), \mathrm{T}_{1 \rho}(\mathrm{C})$ and $\mathrm{T}_{\mathrm{CH}}$ values obtained from each peak in the ${ }^{13} \mathrm{C}$ spectra of all the samples are reported in Table 3. 


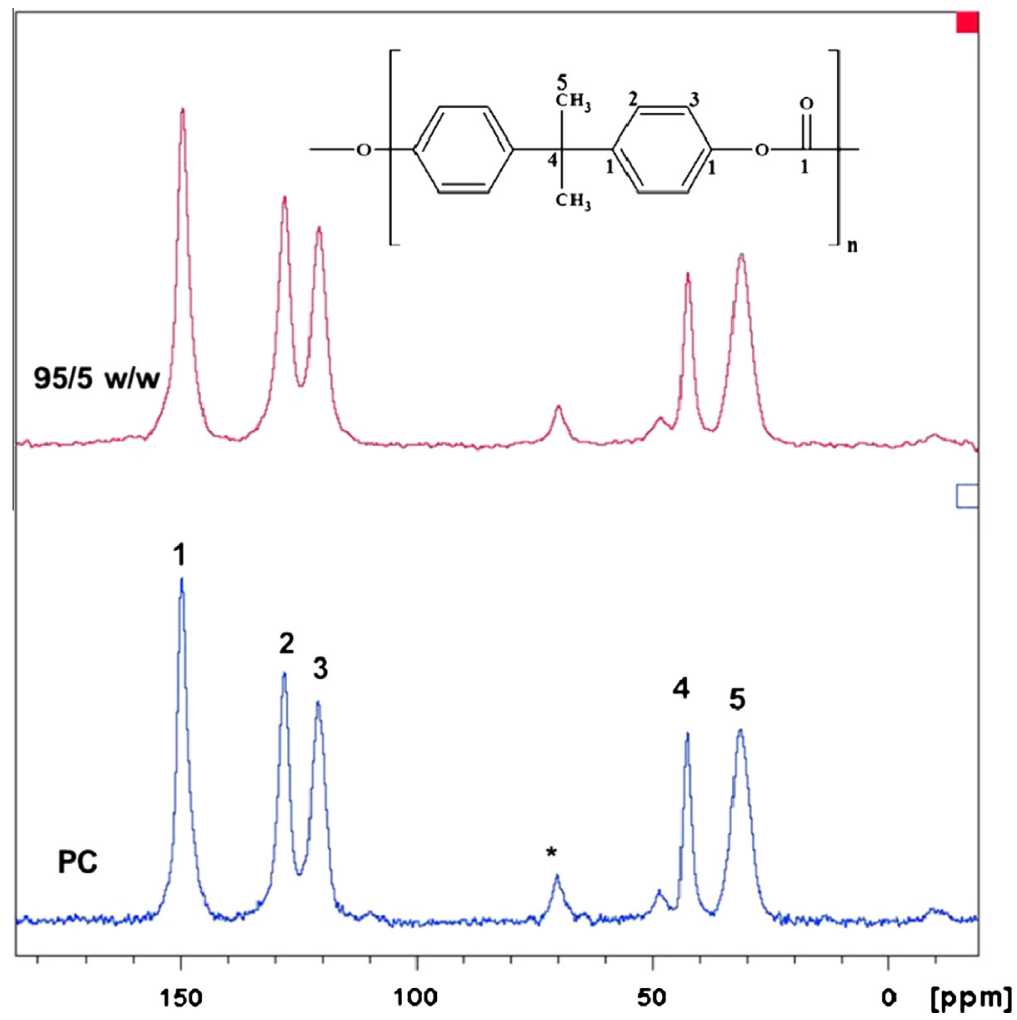

Fig. 11. ${ }^{13} \mathrm{C}\left\{{ }^{1} \mathrm{H}\right\}$ CP-MAS NMR spectra of PC and PC-zirconia nanocomposite loaded with 5 wt.\% of zirconia. Numbers on the peaks identify the carbon atoms. The * symbol indicates spinning sidebands.

Table 3

$\mathrm{T}_{1}(\mathrm{H}), \mathrm{T}_{1 \rho}(\mathrm{H}), \mathrm{T}_{1 \rho}(\mathrm{C})$ and $\mathrm{T}_{\mathrm{CH}}$ values for all the carbons in the ${ }^{13} \mathrm{C}$ spectra of PC and the $95 / 5 \mathrm{w} / \mathrm{w}$ PC-zirconia nanocomposite.

\begin{tabular}{|c|c|c|c|c|c|c|c|c|c|}
\hline \multirow[t]{2}{*}{ Carbon } & \multirow[t]{2}{*}{ ppm } & \multicolumn{2}{|l|}{$\mathrm{T}_{1}(\mathrm{H})(\mathrm{s})$} & \multicolumn{2}{|c|}{$\mathrm{T}_{1 \rho}(\mathrm{H})(\mathrm{ms})$} & \multicolumn{2}{|c|}{$\mathrm{T}_{1 \rho}(\mathrm{C})(\mathrm{ms})$} & \multicolumn{2}{|l|}{$\underline{\mathrm{T}_{\mathrm{CH}}(\mathrm{ms})}$} \\
\hline & & PC & 95/5 w/w PC- $-\mathrm{ZrO}_{2}$ & PC & $\begin{array}{l}95 / 5 \mathrm{w} / \mathrm{w} \\
\mathrm{PC}-\mathrm{ZrO}_{2}\end{array}$ & PC & $\begin{array}{l}95 / 5 \mathrm{w} / \mathrm{w} \\
\mathrm{PC}-\mathrm{ZrO}_{2}\end{array}$ & PC & $\begin{array}{l}95 / 5 \mathrm{w} / \mathrm{w} \\
\mathrm{PC}-\mathrm{ZrO}_{2}\end{array}$ \\
\hline 1 & 149 & $0.39 \pm 0.02$ & $0.43 \pm 0.03$ & $4.9 \pm 0.2$ & $5.3 \pm 0.3$ & $41 \pm 0.2$ & $43.4 \pm 0.8$ & $1328 \pm 127$ & $1211 \pm 92$ \\
\hline 2 & 127.5 & $0.41 \pm 0.03$ & $0.40 \pm 0.02$ & $5.4 \pm 0.2$ & $5.3 \pm 0.2$ & $10.9 \pm 0.1$ & $9.6 \pm 0.9$ & $117 \pm 28$ & $183 \pm 31$ \\
\hline 3 & 120 & $0.39 \pm 0.01$ & $0.42 \pm 0.02$ & $5.2 \pm 0.2$ & $5.2 \pm 0.3$ & $10.2 \pm 0.2$ & $9.4 \pm 0.9$ & $64 \pm 12$ & $151 \pm 22$ \\
\hline 4 & 42 & $0.40 \pm 0.01$ & $0.42 \pm 0.01$ & $4.8 \pm 0.2$ & $5.1 \pm 0.4$ & $18 \pm 0.2$ & $35.1 \pm 0.7$ & $1059 \pm 97$ & $831 \pm 62$ \\
\hline 5 & 31 & $0.42 \pm 0.01$ & $0.41 \pm 0.02$ & $4.9 \pm 0.3$ & $5.0 \pm 0.3$ & $19.2 \pm 0.1$ & $33.3 \pm 0.4$ & $275 \pm 20$ & $239 \pm 16$ \\
\hline
\end{tabular}

The presence of the filler in the PC matrix did not significantly affect the $T_{1}(H)$ and $T_{1 \rho}(H)$ values. This indicates that the spin diffusion phenomenon averaged the dynamic behavior of the polymer and that the composites were dynamically homogeneous in a range from tens to hundreds of nanometres. On the contrary, in the PC-zirconia nanocomposite the $T_{1 \rho}(C)$ values for peaks 1,2 and 3 were unchanged, while the values for peaks 4 and 5 relative to the quaternary carbon bonded to the methyl groups and of the methyl carbons were higher than the ones for the pure PC. In addition, an increase in the dipolar coupling $\mathrm{T}_{\mathrm{CH}}$ for the protonated aromatic carbons is observed. This implies that the main motions involving this part of the polymeric chain are hindered by the presence of zirconia, indicates specific intermolecular interactions. These interactions slightly involved the protonated aromatic carbons.

\section{Conclusions}

The zirconia nanoparticles, organized in clusters uniformly dispersed in polycarbonate, did not change the polymer structure, but induced a modification in the organization of the PC chains. DMA showed that the polymer chain immobilization became significant at $5 \%$ zirconia content. The thermal degradation process seems to depend on the amount of zirconia, and the accompanying differences in particle size and PC-zirconia interaction. NMR analysis shows intermolecular interactions between zirconia and the polymer, in particular with the quaternary carbon bonded to the methyl groups and the methyl carbons. These interactions could be responsible for the differences in the polymer chain mobility and thermal degradation mechanism. The ordered structure induced by the nano- 
particles and strong interfacial interactions between the PC and zirconia could also account for the observed differences.

\section{Acknowledgements}

The National Research Foundation in South Africa and the University of the Free State are acknowledged for financial support of the research. TEM and NMR experimental data were provided by Centro Grandi Apparecchiature-UniNetLab-Universitá di Palermo funded by P.O.R. Sicilia 2000-2006, Misura 3.15 Azione C Quota Regionale.

\section{References}

[1] Lagashetty A, Vijayanand H, Basavaraja S, Bedre MD, Venkataraman A. Preparation, characteristics, and thermal studies of $\gamma-\mathrm{Fe}_{2} \mathrm{O}_{3}$ and $\mathrm{CuO}$ dispersed polycarbonate nanocomposites. J Therm Anal Calorim 2010;99:577-81. http://dx.doi.org/10.1007/s10973-009-0475-8.

[2] Carrion FJ, Sanes J, Bermudez MD. Influence of $\mathrm{ZnO}$ nanoparticle filler on the properties and wear resistance of polycarbonate. Wear 2007;262:1504-10. http://dx.doi.org/10.1016/j.wear.2007.01.016.

[3] Carrion FJ, Sanes J, Bermudez MD. Effect of ionic liquid on the structure and tribological properties of polycarbonate- zinc oxide nanodispersion. Mater Lett 2007;61:4531-5. http://dx.doi.org/ 10.1016/j.matlet.2007.02.044.

[4] Dolores BM, Vilches BWC, José FS. Scratch resistance of polycarbonate containing $\mathrm{ZnO}$ nanoparticles: effect of sliding direction. J Nanosci Nanotechnol 2010;10:6683-9. http:// dx.doi.org/10.1166/inn.2010.2513.

[5] Meri RM, Shutka A, Zalite I, Bledzki AK. Metal oxide mineral filler containing polymer nanocomposites. Solid State Phenom 2009;151:154-8. http://dx.doi.org/10.4028/www.scientific.net/ SSP.151.154.

[6] $\mathrm{Wu} \mathrm{L}$, Chen $\mathrm{P}$, Zhang J, He J. Inhibited transesterification and enhanced fibrillation of TLCP by nano- $\mathrm{SiO}_{2}$ in polycarbonate matrix. Polymer 2006;47:448-56. http://dx.doi.org/10.1016/ j.polymer.2005.11.044.

[7] Dong Q, Gao C, Ding Y, Wang F, Wen B, Zhang S, et al. A polycarbonate/magnesium oxide nanocomposite with high flame retardancy. J Appl Polym Sci 2011;123:1085-93. http://dx.doi.org/ 10.1002/app.34574.

[8] Eitan A, Fisher FT, Andrews R, Brinson LC, Schadler LS. Reinforcement mechanisms in MWCNT-filled polycarbonate. Compos Sci Technol 2006;66:1162-73. j.compscitech.2005.10.004.

http://dx.doi.org/10.1016/

[9] Feng J, Hao J, Du J, Yang R. Effects of organoclay modifiers on the flammability, thermal and mechanical properties of polycarbonate nanocomposites filled with a phosphate and orgarnoclays. Polym Degrad Stab 2012;97:108-17. http://dx.doi.org/10.1016/ j.polymdegradstab.2011.09.019.

[10] Feng J, Hao J, Du J, Yang R. Using TGA/FTIR TGA/MS and cone calorimetry to understand thermal degradation and flame retardancy mechanism of polycarbonate filled with solid bisphenol A bis(biphenyl phosphate) and montmorillonite. Polym Degrad Stab 2012;97:605-14. j.polymdegradstab.2012.01.011.

[11] Wang S, Hu Y, Wang Z, Yong T, Chen Z, Fan W. Synthesis and characterization of polycarbonate/ABS/montmorillonite nanocomposites. Polym Degrad Stab 2003;80:157-61. http:// dx.doi.org/10.1016/S0141-3910(02)00397-X.

[12] Imai Y, Terahara A, Hakuta Y, Matsui K, Hayashi H, Ueno N. Transparent poly(bisphenol A carbonate)-based nanocomposites with high refractive index nanoparticles. Eur Polym J 2009;45:630-8. http://dx.doi.org/10.1016/J.europolyj.2008.12.013.

[13] Xu K, Zhou S, Wu L. Effect of highly dispersible zirconia nanoparticles on the properties of UV-curable poly(urethaneacrylate) coatings. J Mater Sci 2009;44:1613-21. http://dx.doi.org/ 10.1007/s10853-008-3231-8.
[14] Luo K, Zhou S, Wu L, You B. Preparation and properties of crosslinked zirconia nanoparticles films on polycarbonate. Thin Solid Films 2010;518:6804-10. $\quad$ http://dx.doi.org/10.1016/ j.tsf.2010.06.035.

[15] Bondioli F, Cannillo V, Fabbri E, Messori M. Preparation and characterization of epoxy resins filled with submicron spherical zirconia particles. Polimery 2006;51:11-2. http://dx.doi.org/ 10.1111/j.1551-2916.2008.02666.x.

[16] Hartmann SR, Hahn EL. Nuclear double resonance in the rotating frame. Phys Rev Online Arch 1962;128:2042-53. http://dx.doi.org/ 10.1103/PhysRev.128.2042.

[17] Lau C, Mi Y. A study of blending and complexation of poly(acrylic acid)/poly(vinyl pyrrolidone). Polymer 2002;43:823-9. http:// dx.doi.org/10.1016/S0032-3861(01)00641-3.

[18] Alamo RG, Blanco JA, Carrilero I. Measurement of the ${ }^{13} \mathrm{C}$ spin-lattice relaxation time of the non-crystalline regions of semicrystalline polymers by a CP-MAS-based method. Polymer 2002;43:1857-65. http://dx.doi.org/10.1016/S0032-3861(01)00761-3.

[19] Conte P, Spaccini R, Piccolo A. State of art of CPMAS ${ }^{13}$ C NMR spectroscopy applied to natural organic matter. Prog Nucl Magn Reson Spectrosc 2004;44:215-23. http://dx.doi.org/10.1016/ j.pnmrs.2004.02.002.

[20] Saladino ML, Motaung TE, Luyt AS, Spinella A, Nasillo G, Caponetti E. The effect of silica nanoparticles on the morphology, mechanical properties and thermal degradation kinetics of PMMA. Polym Degrad Stab 2012;97:452-9. http://dx.doi.org/10.1016/ i.polymdegradstab.2011.11.006.

[21] Motaung TE, Luyt AS, Saladino ML, Martino DC, Caponetti E. Morphology, mechanical properties and thermal degradation kinetics of PMMA-zirconia composites prepared by melt compounding. eXPRESS. Polym Lett 2012;6:871-81. http:// dx.doi.org/10.3144/expresspolymlett.2012.93.

[22] Richter S, Saphiannikova M, Jehnichen D, Bierdel M, Heinrich G. Experimental and theoretical studies of agglomeration effects in multi-walled carbon nanotube-polycarbonate melts. eXPRESS. Polym Lett 2009;3:753-68. doi:103144/expresspolymlett.2009.94.

[23] Cheung YW, Stein RS, Wignall GD, Yang HE. Small-angle scattering investigations of $\operatorname{poly}(\varepsilon$-caprolactone)/polycarbonate blends. 1 . Small-angle neutron and X-ray scattering study of crystalline blend morphology. Macromolecules 1993;26:5365-71. http:// dx.doi.org/10.1021/ma00072a012.

[24] Nallet F, Roux D, Milner STJ. Small-angle scattering features of lyotropic smectics A. Journal de Physique 1990;51:2333-46. http:// dx.doi.org/10.1051/jphys:0199000510200233300.

[25] McNeill IC, Rincon A. Degradation studies of some polyesters and polycarbonates -8 . Bisphenol A polycarbonate. Polym Degrad Stab 1991;31:163-80. http://dx.doi.org/10.1016/0141-3910(91)90072-Y.

[26] Zong R, Hu Y, Wang S, Song L. Thermogravimetric evaluation of PC/ ABS/montmorillonite nanocomposite. Polym Degrad Stab 2004;83:423-8. i.polymdegradstab.2003.09.004.

[27] Motaung TE, Luyt AS, Bondioli F, Messori M, Saladino ML, Spinella A, et al. PMMA-titania nanocomposites: properties and thermal degradation behaviour. Polym Degrad Stab 2012;97:1325-33. http://dx.doi.org/10.1016/j.polymdegradstab.2012.05.022.

[28] Holland BJ, Hay JN. The value and limitations of non-isothermal kinetics in the study of polymer degradation. Thermochim Acta 2002;388:253-73. 6031(02)00034-5.

http://dx.doi.org/10.1016/S0040-

9] Gao Z, Kaneko T, Hou D, Nakada M. Kinetics of thermal degradation of poly(methyl methacrylate) studied with the assistance of the fractionation conversion at the maximum reaction rate. Polym Degrad Stab 2004;84:399-403. http://dx.doi.org/10.1016/ i.polymdegradstab.2003.11.015.

[30] Jang BN, Wilkie CA. The thermal degradation of bisphenol A polycarbonate in air. Thermochim Acta 2005;426:73-84. http:// dx.doi.org/10.1016/i.tca.2004.07.023.

[31] Eijkelenboom APAM, Maas WEJR, Veeman WS, Buning GHW, Vankan JMJ. Triple-resonance fluorine-19, proton, and carbon-13 CP-MAS NMR study of the influence of PMMA tacticity on the miscibility in PMMA/poly(vinylidene fluoride) (PVF2) blends. Macromolecules 1992;25:4511-8. http://dx.doi.org/10.1021/ma00044a009. 